\title{
A review of wearable sensors based monitoring with daily physical activity to manage type 2 diabetes
}

\author{
Omar AlShorman ${ }^{1}$, Buthaynah AIShorman ${ }^{2}$, Fahed Alkahtani ${ }^{3}$ \\ ${ }^{1}$ Electrical Engineering Department, Faculty of Engineering, Najran University, Saudi Arabia \\ ${ }^{1}$ AlShrouk Trading Company, Najran University, Saudi Arabia \\ ${ }^{2}$ South Alternative Center for Physiotherapy and Rehabilitation, Saudi Arabia \\ ${ }^{3}$ Electrical Engineering Department, Faculty of Engineering, Najran University, Saudi Arabia
}

\begin{tabular}{|c|c|}
\hline Article Info & ABSTRACT \\
\hline Article history: & Globally, the aging and the lifestyle lead to rabidly increment of the number \\
\hline Received Feb 3, 2020 & $\begin{array}{l}\text { of type two diabetes (T2D) patients. Critically, T2D considers as one of } \\
\text { the most challenging healthcare issue. Importantly, physical activity (PA) }\end{array}$ \\
\hline Revised Jun 30, 2020 & plays a vital role of improving glycemic control T2D. However, daily \\
\hline Accepted Jul 11, 2020 & $\begin{array}{l}\text { monitoring of T2D using wearable devices/ sensors have a crucial role to } \\
\text { monitor glucose levels in the blood. Nowadays, daily physical activity (PA) }\end{array}$ \\
\hline Keywords: & $\begin{array}{l}\text { and exercises have been used to manage T2D. The main contribution of } \\
\text { the proposed study is to review the literature about managing and monitoring }\end{array}$ \\
\hline $\begin{array}{l}\text { Diabetes } \\
\text { Healthcare }\end{array}$ & $\begin{array}{l}\text { T2D with daily PA through wearable devices and sensors. Finally, challenges } \\
\text { and future trends are also highlighted. }\end{array}$ \\
\hline
\end{tabular}

Monitoring

Physical activity

Sensor

This is an open access article under the CC BY-SA license.

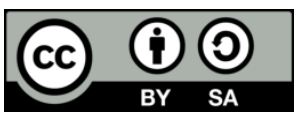

\section{Corresponding Author:}

Omar AlShorman,

Electrical Engineering Department, and AlShrouk Trading Company,

Njran University,

Najran, Saudi Arabia.

Email: omar2007_ahu@yahoo.com

\section{INTRODUCTION}

Nowadays, decreasing chronic diseases by changing the health behavior and improving lifestyle are critically required $[1,2]$. Importantly, the use of recent trends and advanced technology in healthcare industries have gain a crucial role [3-5]. However, achieve high safety living [6-8] for elderly and patients is challenged. Thus, healthcare monitoring/tracking for those people are vital [9]. According the World Health Organization (WHO) reports, the number of T2D patients is 422 million in 2014. That means $8.5 \%$ of adults serve from diabetes. However, WHO expects that the number will arrive to 500 million in 2030 [10]. Furthermore, there is a direct contribution between T2D and some conditions, including, stroke, heart disease, dental problems, pregnancy problems, immune system problems, nervous system disease, kidney failure, blindness, and high blood pressure [11]. In addition, diabetic patients treatment creates huge costs for instituations and goverments [12].

Physical activity (PA) [13-15] plays an important role of improving glycemic control [16] in type 2 diabetes (T2D) as shown in Figure 1 [17]. Moreover, PA achieves several healthcare goals such as [18, 19], reducing the risk of cardiovascular disease (CVD) [20, 21], increasing the vigour [22], reducing levels of triglyceride-rich VLDL [23], decreasing the insulin resistance [24, 25], improving the blood pressure (BP) [26, 27], preventing the obesity [28, 29], reducing the mortality [30, 31], improving physical 
fitness [32, 33], enhance cognitive performance [34], enhance the mood [35], and increasing the energy expenditure $[36,37]$.

In recent years, several glucose-monitoring techniques have been conducted [38-42]. Based on the literature, still there is a lack of clarity about what level of physical activity is needed to reduce the risk of T2D [43, 44]. However, it is not clear which type of PA is better in reducing T2D risk than others. This lacking of clarity leads to the contribution of the proposed study [45-47]. The main contribution of the proposed study is to manage T2D by using wearable devices and sensors with daily physical activity. Figure 2 shows the flow chart of managing and monitoring type 2 diabetes using daily physical activity through wearable sensors. Intensity and duration are the main two measures to classify PA [48]. The metabolic equivalent (MET) is used to measure the intensity of PA [49, 50]. Table 1 shows daily physical activities and their MET.

Wearable devices [51] are now highly used for human activity recognition [52]. They are used as a predictor for any abnormal health cases [53, 54]. Importantly, diabetes patients critically need 24/7 management [55]. Monitoring the blood glucose (BG) level using wearable sensors has a vital role in diabetes treatment revolution nowadays [56-58].

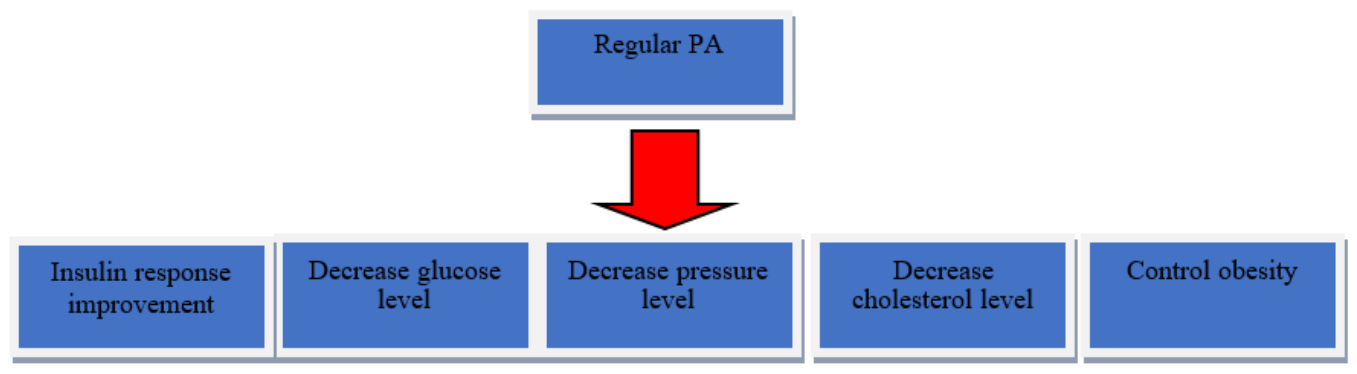

Figure 1. The effect of regular physical activity on T2D

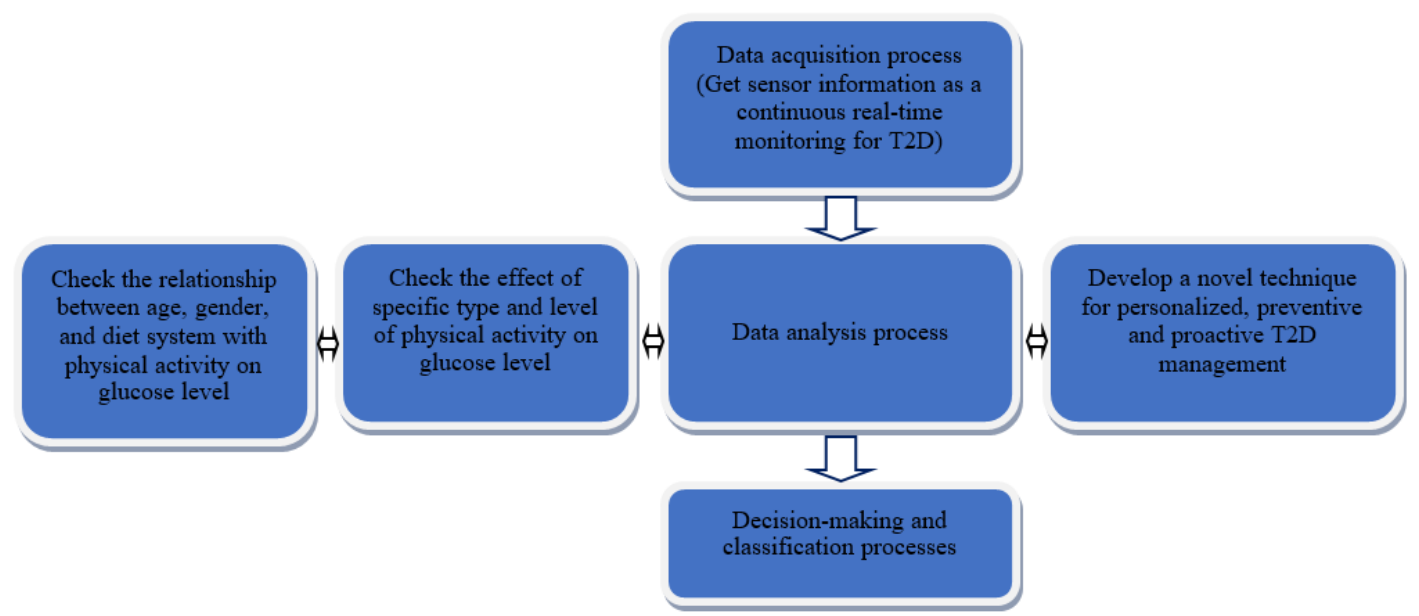

Figure 2. The flow chart of managing and monitoring type 2 diabetes using daily physical activity through wearable sensors

Table 1. Daily physical activities and their MET

\begin{tabular}{cc}
\hline Daily PA & MET \\
\hline Housework & $1.8-4$ \\
Gardening & 3.8 \\
Shoveling & 6 \\
Slow walking & 3 \\
Fast Walking & 9 \\
\hline
\end{tabular}


Table 2 shows wearable sensing technologies [59-61]. The proposed study aims to review wearable sensing technologies used to mangae and monitor T2D with PA. Morover, challenges and future trends are highlighted.

Table 2. Wearable sensing technologies

\begin{tabular}{ll}
\hline Sensor type & Example \\
\hline Inertial sensor [62, 63] & Magnetic field sensors [64], pressure sensors [65], and accelerometer [66] \\
Image sensor [67] & Camera [68] \\
Location sensor [69, 70] & GPS and GIS [71] \\
Physiological sensor [72, 73] & $\begin{array}{l}\text { Galvanic skin [74], puls rate [75], electroencephalogram (EEG) [76, 77], electrocardiogram } \\
\text { (ECG) [78], blood pressure sensor [79], electrooculography (EOG) [80], and spirometer [81] }\end{array}$ \\
\hline
\end{tabular}

\section{LITERATUR REVIEW}

Several studies and researches have been conducted to study the relationship between physical activity and T2D. That include:

- $\quad$ Internet of things (IoT) [82]

- $\quad$ Big data analytics [83]

- $\quad$ Signal processing based techniques [84]

- $\quad$ Image processing based techniques [85]

- $\quad$ Intelligent techniques [86]

- Data fusion techniques [87]

- $\quad$ Data mining techniques [88]

- $\quad$ Expert Systems [89]

Table 3 shows the literature of the proposed study.

Table 3. Recent advances on PA and T2D

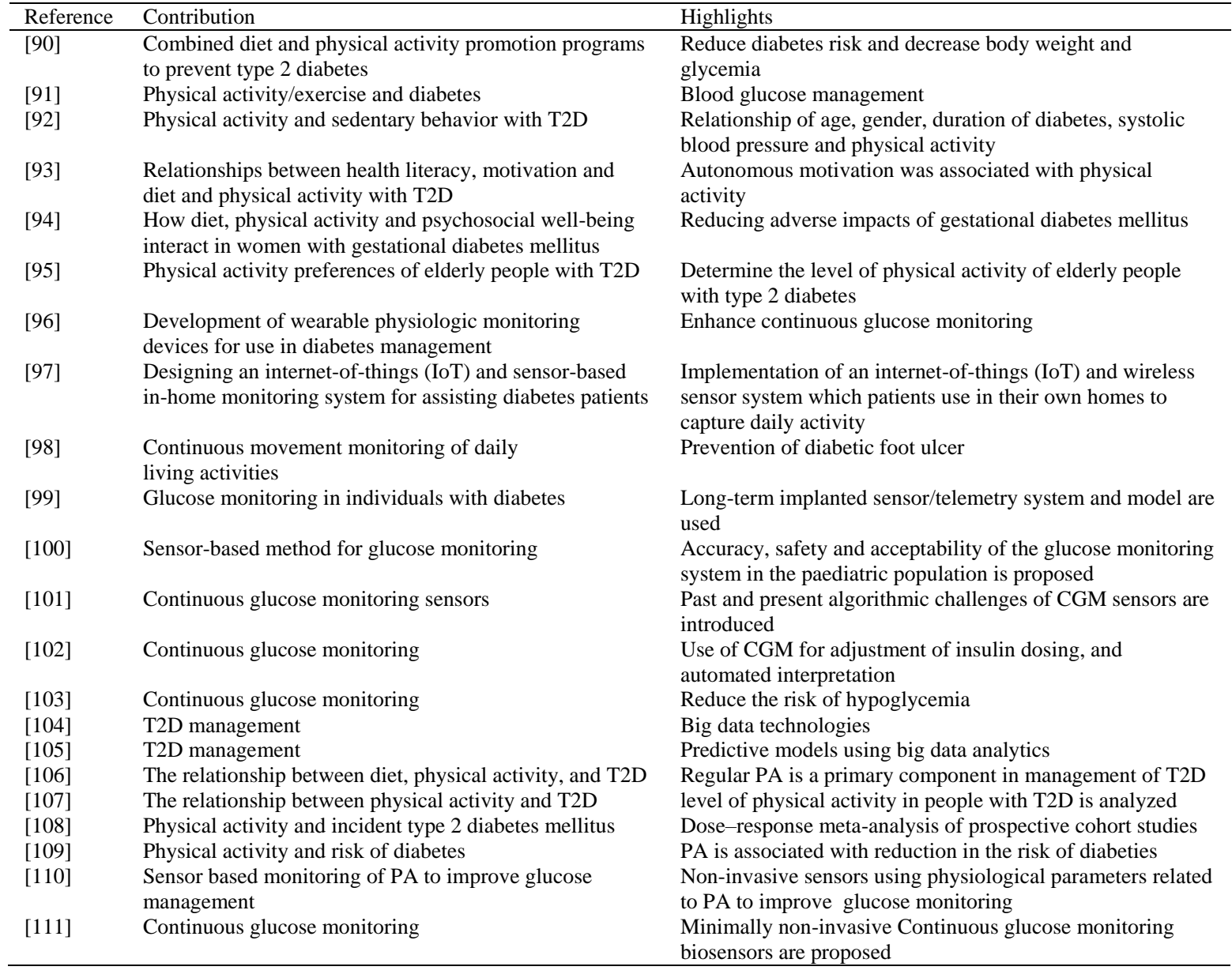




\section{CHALLENGES}

This section summarizes challenges and future trends for wearable sensors based monitoring with daily physical activity to manage type 2 diabetes, including [101, 102, 112-114]:

- PA level: yet, there is a lack of clarity about what level of PA is needed to reduce the risk of T2D.

- PA Diversity: definition of the activities characteristics is challenging issue.

- Accuracy: does continuous glucose monitoring is accurate enough to be reliable measure for glucose level for dosing insulin.

- Privacy and security: helatcare data is sensitive data.

- Availability: detect failures of the sensor is very crucial.

- Cost: continuous monitoring is very costly process.

- Patient acceptance: the wearable device sould be acceptable and comfortable by the wearer, in terms of, size, shape, design, skin placement, and safty.

- Sensor calibration: reduce the impact of individual quasi-stable factors is critical.

- $\quad$ Energy efficiency: continuous monitoring is energy consuming.

- $\quad$ Noise and uncontrolled environment: background noise may affect performance, accuracy, precision.

- Big data, Bandwidth, and computational time: continuous monitoring provides a huge amount of data $[115,116]$.

\section{CONCLUSION}

Recent advances in the healthcare enhance healthcare industris and medical services. However, the latest advances of technology and communication, such as internet of things (IoT) have a vital role in disease diagnosis and monitoring. However, the internet of medical things (IoMT) has an ability to continuous and remote real-time monitoring of T2D. However, PA plays an important role of improving glycemic control. Imbortantly, wearable devices/sensors have the potential to monitor continuously and non-invasively T2D. The main aim of the proposed review study is to find visible solutions to enhance the healthcare living facilities using remote health monitoring (RHM). Moreover, the proposed review study highlighted wearable sensors based monitoring with daily physical activity to manage type 2 diabetes. Furthermore, personalized, continuous, preventive and proactive diabetes management is also proposed. Finally, challenges and future trends are discussed and highlighted.

\section{REFERENCES}

[1] A. Afshin, et al., "Information technology and lifestyle: a systematic evaluation of internet and mobile interventions for improving diet, physical activity, obesity, tobacco, and alcohol use," Journal of the American Heart Association, vol. 5, p. e003058, 2016.

[2] K. Bhagchandani and D. P. Augustine, "IoT based heart monitoring and alerting system with cloud computing and managing the traffic for an ambulance in India," International Journal of Electrical and Computer Engineering (IJECE), vol. 9, no. 6, pp. 5068-5074, 2019.

[3] R. Bailey, et al., "Realising the benefits of sports and physical activity: the human capital model," RETOS. Nuevas Tendencias en Educación Física, Deporte y Recreación, pp. 147-154, 2015.

[4] B. A. Lewis, et al., "Future directions in physical activity intervention research: expanding our focus to sedentary behaviors, technology, and dissemination," Journal of behavioral medicine, vol. 40, pp. 112-126, 2017.

[5] D. Gupta, et al., "Integrated healthcare monitoring device for obese adults using internet of things (IoT)," International Journal of Electrical \& Computer Engineering, vol. 10, no. 2, pp. 1239-1247, 2020.

[6] H. Yhdego, et al., "Towards musculoskeletal simulation-aware fall injury mitigation: transfer learning with deep CNN for fall detection," in 2019 Spring Simulation Conference (SpringSim), pp. 1-12, 2019.

[7] A. Chan, et al., "Fall detection using machine learning," Google Patents, 2019.

[8] F. J. Thilo, et al., "Usability of a wearable fall detection prototype from the perspective of older people-A real field testing approach," Journal of clinical nursing, vol. 28, pp. 310-320, 2019.

[9] M. A. Al-Dhaheri, et al., "Noninvasive blood glucose monitoring system based on near-infrared method," International Journal of Electrical \& Computer Engineering, vol. 10, no. 2, pp. 1736-1746, 2020.

[10] G. Cappon, et al., "Wearable continuous glucose monitoring sensors: a revolution in diabetes treatment," Electronics, vol. 6, p. 65, 2017.

[11] J. A. Hawley and J. R. Zierath, "Physical activity and type 2 diabetes: therapeutic effects and mechanisms of action," Human Kinetics, 2008.

[12] A. Viljoen, et al., "Evaluation of the long-term cost-effectiveness of once-weekly semaglutide versus dulaglutide for treatment of type 2 diabetes mellitus in the UK," Diabetes, Obesity and Metabolism, vol. 21, pp. 611-621, 2019.

[13] H. People, "Physical activity," Washington, DC: US Department of Health \& Human Services, 2020. 
[14] H. Kim, et al., "Developing a Physical Activity Ontology to Support the Interoperability of Physical Activity Data," Journal of medical Internet research, vol. 21, p. e12776, 2019.

[15] A. Rghioui and A. Oumnad, "Internet of Things: Surveys for Measuring Human Activities from Everywhere," International Journal of Electrical \& Computer Engineering, vol. 7, no. 5, pp. 2474-2482, 2017.

[16] E. F. Andrade, et al., "Mechanisms involved in glycemic control promoted by exercise in diabetics," Current diabetes reviews, vol. 15, pp. 105-110, 2019.

[17] H. Hamasaki, "Daily physical activity and type 2 diabetes: a review," World journal of diabetes, vol. 7, p. 243, 2016.

[18] R. J. Sigal, et al., "Physical activity and diabetes," Canadian journal of diabetes, vol. 42, pp. S54-S63, 2018.

[19] Y. Park, et al., "The Effect of Exercise on Endothelial Function and Glycemic Control in Type 2 Diabetes: Metaanalysis," Medicine \& Science in Sports \& Exercise, vol. 50, pp. 541-542, 2018.

[20] C. J. Lavie, et al., "The role of physical fitness in cardiovascular disease prevention," The Medical Roundtable General Medicine Edition, vol. 1, no. 2, pp. 152-163, 2012.

[21] N. A. Ricci and A. I. L. Cunha, "Physical Exercise for Frailty and Cardiovascular Diseases," in Frailty and Cardiovascular Diseases, pp. 115-129, 2020.

[22] Y. A. Balk, et al., “"What a match!”: the specific role of resources in the relation between demands and vigour in elite sport," Applied Psychology, vol. 69, pp. 120-147, 2020

[23] S. Khan and G. Jena, "Sodium butyrate reduces insulin-resistance, fat accumulation and dyslipidemia in type-2 diabetic rat: A comparative study with metformin," Chemico-biological interactions, vol. 254, pp. 124-134, 2016.

[24] M. E. Chen and T. S. Hannon, "Clinical Manifestations of Insulin Resistance in Youth," in Insulin Resistance, pp. 3-17, 2020.

[25] A. M. Savolainen, et al., "Physical Activity Associates with Muscle Insulin Sensitivity Postbariatric Surgery," Medicine and science in sports and exercise, vol. 51, p. 278, 2019.

[26] W. Yan, et al., "Physical activity and blood pressure during pregnancy: Mediation by anxiety symptoms," Journal of affective disorders, vol. 264, pp. 376-382, 2020.

[27] S. Köchli, et al., "Obesity, High Blood Pressure, and Physical Activity Determine Vascular Phenotype in Young Children: The EXAMIN YOUTH Study," Hypertension, vol. 73, pp. 153-161, 2019.

[28] M. Benusic and L. J. Cheskin, "Obesity prevalence in large US cities: association with socioeconomic indicators, race/ethnicity and physical activity," Journal of public health, 2019.

[29] W. Y. Huang and S. H. S. Wong, "Prospective associations between weekend catch-up sleep, physical activity, and childhood obesity," Childhood Obesity, vol. 15, pp. 40-47, 2019.

[30] G. Cárdenas-Fuentes, et al., "Multiple approaches to associations of physical activity and adherence to the Mediterranean diet with all-cause mortality in older adults: the PREvención con DIeta MEDiterránea study," European journal of nutrition, vol. 58, pp. 1569-1578, 2019.

[31] U. Ekelund, et al., "Do the associations of sedentary behaviour with cardiovascular disease mortality and cancer mortality differ by physical activity level? A systematic review and harmonised meta-analysis of data from 850 060 participants," British journal of sports medicine, vol. 53, pp. 886-894, 2019.

[32] S. Haible, et al., "Physical Activity-Related Health Competence, Physical Activity, and Physical Fitness: Analysis of Control Competence for the Self-Directed Exercise of Adolescents," International Journal of Environmental Research and Public Health, vol. 17, p. 39, 2020.

[33] L. Pérusse, "Genetic Variation in the Response to Exercise Training: Impact on Physical Fitness and Performance," in Principles of Nutrigenetics and Nutrigenomics, pp. 187-196, 2020.

[34] T. McMorris, "Physical activity and cognition in children and adolescents," International Journal of Sport and Exercise Psychology, vol. 17, pp. 179-181, 2019.

[35] J. S. Chan, et al., "Special Issue-Therapeutic Benefits of Physical Activity for Mood: A Systematic Review on the Effects of Exercise Intensity, Duration, and Modality," The Journal of psychology, vol. 153, pp. 102-125, 2019.

[36] J. C. Lee, et al., "Physical activity energy expenditure and cardiometabolic health in three rural Kenyan populations," American Journal of Human Biology, vol. 31, p. e23199, 2019.

[37] K. R. Westerterp, "Measurement of Energy Expenditure," in Translational Research Methods in Diabetes, Obesity, and Nonalcoholic Fatty Liver Disease, pp. 101-119, 2019.

[38] N. A. B. A. Salam, et al., "The evolution of non-invasive blood glucose monitoring system for personal application," Journal of Telecommunication, Electronic and Computer Engineering (JTEC), vol. 8, pp. 59-65, 2016.

[39] F. Lucertini, et al., "Discontinuously supervised aerobic training vs. physical activity promotion in the selfmanagement of type 2 diabetes in older Italian patients: design and methods of the "TRIPL-A'randomized controlled trial," BMC geriatrics, vol. 19, p. 11, 2019.

[40] T. Gajanand, et al., "Comparing the Efficacy of Supervised and Unsupervised Exercise Training on Glycaemic Control in Type 2 Diabetes: A Systematic Review," Current diabetes reviews, vol. 16, no. 6, pp. 570-579, 2020.

[41] A. Abdullah, et al., "Glycemic control in Kuwaiti diabetes patients treated with glucose-lowering medication," Primary Care Diabetes, vol. 14, no. 4, pp. 311-316, 2020.

[42] S. Raghavendra and J. S. Kumar, "Performance evaluation of random forest with feature selection methods in prediction of diabetes," International Journal of Electrical \& Computer Engineering, vol. 10, no. 1, pp. 353-359, 2020 . 
[43] D. Aune, et al., "Physical activity and the risk of type 2 diabetes: a systematic review and dose-response metaanalysis," European Journal of Epidemiology, vol. 30, no. 7, pp. 529-542, 2015.

[44] P. Jones, et al., "Prediction of diabetic foot ulceration: The value of using microclimate sensor arrays," Journal of diabetes science and technology, vol. 14, pp. 55-64, 2020.

[45] L. M. Russo, et al., "Physical activity interventions in pregnancy and risk of gestational diabetes mellitus: a systematic review and meta-analysis," Obstetrics \& Gynecology, vol. 125, pp. 576-582, 2015.

[46] A. D. Association, "5. Prevention or delay of type 2 diabetes," Diabetes Care, vol. 40, pp. S44-S47, 2017.

[47] M. B. Kongstad, et al., "Effectiveness of remote feedback on physical activity in persons with type 2 diabetes: A systematic review and meta-analysis of randomized controlled trials," Journal of telemedicine and telecare, vol. 25, pp. 26-34, 2019.

[48] J. Tarp, et al., "Cardiorespiratory fitness, muscular strength and risk of type 2 diabetes: a systematic review and meta-analysis," Diabetologia, vol. 62, no. 7, pp. 1129-1142, 2019.

[49] C. de O. Santini, et al., "Do the body mass index and the diagnosis of gestational diabetes mellitus influence the level of physical activity during pregnancy and postpartum?" PloS one, vol. 14, no. 8, p. e0220947, 2019.

[50] S. Balducci, et al., "Effect of a Behavioral Intervention Strategy on Sustained Change in Physical Activity and Sedentary Behavior in Patients with Type 2 Diabetes: The IDES_2 Randomized Clinical Trial,” Jama, vol. 321, pp. 880-890, 2019.

[51] M. Niswar, et al., "A low cost wearable medical device for vital signs monitoring in low-resource settings," International Journal of Electrical \& Computer Engineering, vol. 9, no. 4, pp. 2321-2327, 2019.

[52] N. A. Sakr, et al., "A multilabel classification approach for complex human activities using a combination of emerging patterns and fuzzy sets," International Journal of Electrical \& Computer Engineering, vol. 9, no. 4, pp. 2993-3001, 2019.

[53] R. Rajasekaran, et al., "Health Monitoring System for Individuals Using Internet of Things," in Incorporating the Internet of Things in Healthcare Applications and Wearable Devices, pp. 150-164, 2020.

[54] A. Ukil and S. Bandyopadhyay, "Automated Cardiac Health Screening Using Smartphone and Wearable Sensors through Anomaly Analytics," in Mobile Solutions and Their Usefulness in Everyday Life, pp. 145-172, 2019.

[55] S. H. Ley, et al., "Prevention and management of type 2 diabetes: dietary components and nutritional strategies," The Lancet, vol. 383, pp. 1999-2007, 2014.

[56] H. Zhao, et al., "Microchip based electrochemical-piezoelectric integrated multi-mode sensing system for continuous glucose monitoring," Sensors and Actuators B: Chemical, vol. 223, pp. 83-88, 2016.

[57] J. Feng, et al., "Multi-model sensor fault detection and data reconciliation: A case study with glucose concentration sensors for diabetes," AIChE Journal, vol. 65, pp. 629-639, 2019.

[58] F. Usman, et al., "A Review of Biosensors for Non-Invasive Diabetes Monitoring and Screening in Human Exhaled Breath," IEEE Access, vol. 7, pp. 5963-5974, 2019.

[59] A. Nag, et al., "Wearable flexible sensors: A review," IEEE Sensors Journal, vol. 17, pp. 3949-3960, 2017.

[60] P. J. Taylor, et al., "Efficacy of Real-Time Continuous Glucose Monitoring to Improve Effects of a Prescriptive Lifestyle Intervention in Type 2 Diabetes: A Pilot Study," Diabetes Therapy, pp. 1-14, 2019.

[61] A. Papagiannaki, et al., "Recognizing physical activity of older people from wearable sensors and inconsistent data," Sensors, vol. 19, p. 880, 2019.

[62] C. N. Gerber, et al., "Reliability of single-day walking performance and physical activity measures using inertial sensors in children with cerebral palsy," Annals of physical and rehabilitation medicine, vol. 19, pp. 3003330038, 2019.

[63] M. Awais, et al., "Physical activity classification using body-worn inertial sensors in a multi-sensor setup," in 2016 IEEE 2nd International Forum on Research and Technologies for Society and Industry Leveraging a better tomorrow (RTSI), pp. 1-4, 2016.

[64] J. M. Maia, et al., "Magnetic field sensors in fused silica fabricated by femtosecond laser micromachining," Journal of Physics: Photonics, vol. 2, no. 1, 2020.

[65] H. Ren, et al., "Transfer-medium-free nanofiber-reinforced graphene film and applications in wearable transparent pressure sensors," ACS nano, vol. 13, pp. 5541-5548, 2019.

[66] Z. Liu, et al., "Novel accelerometer realized by a polarization-maintaining photonic crystal fiber for railway monitoring applications," Optics express, vol. 27, pp. 21597-21607, 2019.

[67] D. J. Lokshin, et al., "System and method for enhanced video image recognition using motion sensors," Google Patents, 2019.

[68] A. S. Vemuri, et al., "Hyperspectral Camera Selection for Interventional Health-care," arXiv preprint arXiv: $1904.02709,2019$.

[69] M. C. Schall Jr., et al., "Evaluation of four sensor locations for physical activity assessment," Applied ergonomics, vol. 53, pp. 103-109, 2016.

[70] S. Saeb, et al., "The relationship between mobile phone location sensor data and depressive symptom severity," PeerJ, vol. 4, p. e2537, 2016.

[71] M. C. A. Voirol, et al., "Understanding and Promoting Clinical Reasoning in Chronic and Multimorbid Conditions: A Call for GPs and Healthcare Professionals," Health, vol. 11, pp. 1338-1346, 2019.

[72] K. Kyriakou, et al., "Detecting moments of stress from measurements of wearable physiological sensors," Sensors, vol. 19, p. 3805, 2019.

[73] T. Elshaarani, et al., "Dextran-crosslinked glucose responsive nanogels with a self-regulated insulin release at physiological conditions," European Polymer Journal, vol. 125, p. 109505, 2020. 
[74] P. P. Ray, et al., "Analysis and monitoring of IoT-assisted human physiological galvanic skin responsefactor for smart e-healthcare," Sensor Review, vol. 39, no. 4, pp. 525-541, 2019.

[75] N. S. Ali, et al., "Real-time Heart Pulse Monitoring Technique Using Wireless Sensor Network and Mobile Application," International Journal of Electrical \& Computer Engineering, vol. 8, no. 6, pp. 5118-5126, 2018.

[76] O. M. AlShorman and A. M. Alshorman, "Frontal lobe and long-term memory retrieval analysis during pre-learning stress using EEG signals," Bulletin of Electrical Engineering and Informatics, vol. 9, no. 1, pp. 141-145, 2020.

[77] O. AlShorman, et al., "EEG Analysis for Pre-learning Stress in the Brain," in Asian Simulation Conference, pp. 447-455, 2017.

[78] A. Mincholé and B. Rodriguez, "Artificial intelligence for the electrocardiogram," Nature medicine, vol. 25, pp. 22-23, 2019

[79] J. Kim, et al., "Soft Wearable Pressure Sensors for Beat-to-Beat Blood Pressure Monitoring," Advanced healthcare materials, vol. 8, p. 1900109, 2019.

[80] A. López, et al., "An Affordable Method for Evaluation of Ataxic Disorders Based on Electrooculography," Sensors, vol. 19, p. 3756, 2019.

[81] C. W. Carspecken, et al., "TeleSpiro: A low-cost mobile spirometer for resource-limited settings," in 2013 IEEE Point-of-Care Healthcare Technologies (PHT), pp. 144-147, 2013.

[82] M. Sujaritha, et al., "An Automatic Diabetes Risk Assessment System Using IoT Cloud Platform," in EAI International Conference on Big Data Innovation for Sustainable Cognitive Computing, pp. 323-327, 2020.

[83] B. A. Abdelhakim, et al., "Architecture of a decision support system based on big data for monitoring type 2 diabetics," International Journal of Intelligent Enterprise, vol. 6, pp. 204-216, 2019.

[84] F. Molinari, et al., "Empirical mode decomposition analysis of near-infrared spectroscopy muscular signals to assess the effect of physical activity in type 2 diabetic patients," Computers in biology and medicine, vol. 59, pp. 1-9, 2015.

[85] P. Porwal, et al., "Automatic retinal image analysis for the detection of diabetic retinopathy," in Biomedical Signal and Image Processing in Patient Care, pp. 146-161, 2018.

[86] G. Magyar, et al., "Anthropomorphic Virtual Assistant to Support Self-care of Type 2 Diabetes in Older People: A Perspective on the Role of Artificial Intelligence," Proceedings of the 14th International Joint Conference on Computer Vision, Imaging and Computer Graphics Theory and Applications, vol. 1, pp. 323-331, 2019.

[87] R. C. King, et al., "Application of data fusion techniques and technologies for wearable health monitoring," Medical engineering \& physics, vol. 42, pp. 1-12, 2017.

[88] E. Georga, "Development of physiological metabolic models in diabetes based on data mining techniques,"

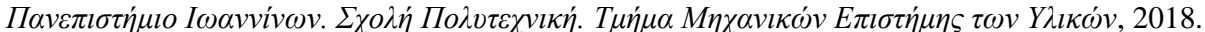

[89] I. Mujawar, et al., "Web-based Fuzzy Expert System for Symptomatic Risk Assessment of Diabetes Mellitus," International Journal of Computer Applications, vol. 182, pp. 5-12, 2018.

[90] E. M. Balk, et al., "Combined diet and physical activity promotion programs to prevent type 2 diabetes among persons at increased risk: a systematic review for the Community Preventive Services Task Force," Annals of internal medicine, vol. 163, pp. 437-451, 2015.

[91] S. R. Colberg, et al., "Physical activity/exercise and diabetes: a position statement of the American Diabetes Association," Diabetes care, vol. 39, pp. 2065-2079, 2016.

[92] D. Dharmastuti, et al., "Associations of physical activity and sedentary behaviour with vision-threatening diabetic retinopathy in Indonesian population with type 2 diabetes mellitus: Jogjakarta Eye Diabetic Study in the Community (JOGED. COM)," Ophthalmic epidemiology, vol. 25, pp. 113-119, 2018.

[93] L. Juul, et al., "Relationships between health literacy, motivation and diet and physical activity in people with type 2 diabetes participating in peer-led support groups," Primary care diabetes, vol. 12, pp. 331-337, 2018.

[94] L. Gilbert, et al., "How diet, physical activity and psychosocial well-being interact in women with gestational diabetes mellitus: an integrative review," BMC pregnancy and childbirth, vol. 19, p. 60, 2019.

[95] I. Crnković, et al., "Physical activity preferences of elderly people with type 2 diabetes who are users of institutional care and local community users," in 6th International Multidisciplinary Scientific Conference SGEM Social Sciences \& Arts Conference, pp. 1-8, 2019.

[96] F. L. Schwartz, et al., "The promise and perils of wearable physiological sensors for diabetes management," Journal of diabetes science and technology, vol. 12, pp. 587-591, 2018

[97] S. Chatterjee, et al., "Designing an Internet-of-Things (IoT) and sensor-based in-home monitoring system for assisting diabetes patients: iterative learning from two case studies," European Journal of Information Systems, vol. 27, pp. 670-685, 2018.

[98] P. Francia, et al., "Continuous movement monitoring of daily living activities for prevention of diabetic foot ulcer: A review of literature," International journal of preventive medicine, vol. 10, p. 22, 2019.

[99] J. Y. Lucisano, et al., "Glucose monitoring in individuals with diabetes using a long-term implanted sensor/telemetry system and model," IEEE Transactions on Biomedical Engineering, vol. 64, pp. 1982-1993, 2017.

[100] J. Edge, et al., "An alternative sensor-based method for glucose monitoring in children and young people with diabetes," Archives of disease in childhood, vol. 102, pp. 543-549, 2017.

[101] A. Facchinetti, "Continuous glucose monitoring sensors: past, present and future algorithmic challenges," Sensors, vol. 16, p. 2093, 2016. 
[102] D. Rodbard, "Continuous glucose monitoring: a review of successes, challenges, and opportunities," Diabetes technology \& therapeutics, vol. 18, pp. S2-3-S2-13, 2016.

[103] E. Toschi and H. Wolpert, "Utility of continuous glucose monitoring in type 1 and type 2 diabetes," Endocrinology and Metabolism Clinics, vol. 45, pp. 895-904, 2016.

[104] R. Bellazzi, et al., "Big data technologies: new opportunities for diabetes management," Journal of diabetes science and technology, vol. 9, pp. 1119-1125, 2015.

[105] S. L. Cichosz, et al., "Toward big data analytics: review of predictive models in management of diabetes and its complications," Journal of diabetes science and technology, vol. 10, pp. 27-34, 2016.

[106] A. Mirahmadizadeh, et al., "Adherence to Medication, Diet and Physical Activity and the Associated Factors Amongst Patients with Type 2 Diabetes," Diabetes Therapy, pp. 1-16, 2020.

[107] C. M. González-Carcelén, et al., "Levels of physical activity in people with diabetes residing in Spain," Atena Journal of Public Health, vol. 2, pp. 1-21, 2020.

[108] A. D. Smith, et al., "Physical activity and incident type 2 diabetes mellitus: a systematic review and doseresponse meta-analysis of prospective cohort studies," Diabetologia, vol. 59, no. 12, pp. 2527-2545, 2016.

[109] H. H. Kyu, et al., "Physical activity and risk of breast cancer, colon cancer, diabetes, ischemic heart disease, and ischemic stroke events: systematic review and dose-response meta-analysis for the Global Burden of Disease Study 2013," BMJ, vol. 354, p. i3857, 2016.

[110] S. Ding and M. Schumacher, "Sensor monitoring of physical activity to improve glucose management in diabetic patients: a review," Sensors, vol. 16, p. 589, 2016.

[111] C. Chen, et al., "Current and emerging technology for continuous glucose monitoring," Sensors, vol. 17, p. 182, 2017.

[112] J. Kim, et al., "Wearable non-invasive epidermal glucose sensors: A review," Talanta, vol. 177, pp. 163-170, 2018.

[113] M. Al-khassaweneh and O. AlShorman, "Frei-Chen Bases Based Lossy Digital Image Compression Technique," Applied Computing and Informatics, pp. 1-14, 2020.

[114] T. Lin, et al., "Non-invasive glucose monitoring: a review of challenges and recent advances," Current Trends in Biomedical Engineering and Biosciences, vol. 6, no. 5, pp. 1-8, 2017.

[115] O. AlShorman, et al., "A Review of Internet of Medical Things (IoMT) - Based Remote Health Monitoring through Wearable Sensors: A Case Study for Diabetic Patients," Indonesian Journal of Electrical Engineering and Computer Science, vol. 20, no. 1, pp. 414-422, 2020.

[116] O. Al-Shorman, "Lossy digital image compression technique using run-length encoding and Frei-Chen basis," Masters' thesis, Yarmouk University, 2012. 